\title{
APUNTES PARA UN MARCO TEÓRICO SOBRE TERRORISMO DE ESTADO EN ARGENTINA Y MÉXICO Francisco García Marañón*
}

RESUMEN: El fenómeno político del Terrorismo de Estado lleva, ineludiblemente, a la reflexión acerca de la desaparición de personas y de los cientos de víctimas civiles de la guerra contra el narcotráfico. Recientemente, desde la perspectiva de los derechos humanos, ha surgido un creciente interés en el estudio del Terrorismo de Estado como un instrumento ilegal e ilegítimo para el ejercicio del poder. Estos apuntes, a partir de herramientas metodológicas basadas en Marx y Bobbio, permiten un primer acercamiento al problema.

$$
\text { sose }
$$

ABSTRACT: State Terrorism inevitably entails us to reflect on the disappearance of people and hundreds of civilian victims of the drug trafficking war. Recently, there has been an increasing interest in the study of State Terrorism, from a human rights perspective, as an illegal and illegitimate tool in the use of power.

PALABRAS CLAVE: Terrorismo de Estado, desaparecidos, oligarquía, guerra sucia, miedo, esquemas comparativos.

KEY WORDS: State Terrorism, missing persons, oligarchy, dirty war, fear, comparative methods.

RECEPCIÓN: 25 de noviembre de 2010.

APROBACIÓN: 18 de febrero de 2011.

* Facultad de Ciencias Políticas, UNAM. 
(C)ITAM Derechos Reservados.

La reproducción total o parcial de este artículo se podrá hacer si el ITAM otorga la autorización previamente por escrito. 


\section{APUNTES PARA UN \\ MARCO TEÓRICO \\ SOBRE TERRORISMO \\ DE ESTADO EN \\ ARGENTINA Y MÉXICO}

\section{De una conceptualización general a ciertas particularidades sobre el Estado}

1 estudio del Terrorismo de Esta-
do puede comprenderse a plenitud a partir de la teoría política marxista, en cuanto que el Estado, para Marx, se presenta como un producto de las contradicciones en la sociedad civil, esto es, una lucha de clases, pues el Estado, para este pensador, es considerado un instrumento de dominación. En su obra La teoría de las formas de gobierno en la historia del pensamiento político, Norberto Bobbio apunta un par de aspectos fundamentales sobre el Estado en Marx y su concepción negativa acerca de éste (frente a otras corrientes de pensamiento político, que le atribuyen bondades organizativas y gregarias): "a) la consideración del Estado como pura y simple superestructura que refleja la situación de las relaciones sociales determinadas por la base social; y, b) la identificación del Estado con el aparato o los aparatos de los que se vale la clase dominante para mantener su dominio". ${ }^{1}$ De modo que define al Estado como el conjunto de las relaciones de producción -la estructura económica de la sociedad-sobre el que se eleva una superestructura jurídica y política, a la que corresponden formas sociales determinadas de conciencia. ${ }^{2}$

${ }^{1}$ Norberto Bobbio, Teoría de las formas de gobierno en la historia del pensamiento político, 1989, México, Fondo de Cultura Económica, 1ª reimpresión, p. 169.

${ }^{2}$ Bobbio, ibid., p. 170. 
Así, las relaciones productivas entre la clase dominante y la dominada -sustanciadas en la explotación del trabajo asalariado por parte del capital- enmarcan con suma claridad la problemática y la razón del Terrorismo de Estado en América Latina. De hecho y, visto de manera inversa, el Terrorismo de Estado comprueba que el estudio de la sociedad, bajo el esquema marxista, sigue vigente. Independientemente de los regímenes y formas de gobierno, el Estado terrorista es un Estado de clase y aplica el terrorismo como un instrumento para el ejercicio del poder. Existen reservas acerca de los regímenes políticos y Estados comunistas contemporáneos; sería motivo de otro estudio la revisión de dichas formas de gobierno que aplicaron prácticas sistemáticas de aniquilamiento y desaparición de personas.

No obstante, en el ámbito de la coerción del Estado, con su inherente violencia, hay que tomar en cuenta que "todo Estado está fundado en la violencia [...] Si solamente existieran configuraciones sociales que ignorasen el medio de la violencia habría desaparecido el concepto de 'Estado' [...] La violencia no es, naturalmente, ni el medio normal ni el único medio de que el Estado se vale, pero sí es su medio específico. Hoy, precisamente, es especialmente íntima la relación del Estado con la violencia". ${ }^{3}$ La salvedad evidente, para el caso del Terrorismo de Estado, radica en el concepto weberiano de violencia física legítima. Para Weber, el elemento conceptual en cuestión es el siguiente:

El Estado moderno es una asociación de dominación con carácter institucional que ha tratado, con éxito, de monopolizar, dentro de un territorio, la violencia física legítima como medio de dominación y, con este fin, ha reunido todos los medios materiales en manos de su dirigente y ha expropiado a todos los funcionarios estamentales que antes disponían de ellos por derecho propio, sustituyéndolos con sus propias jerarquías supremas. ${ }^{4}$

${ }^{3}$ Max Weber, El politico y el cientifico, 1998, Madrid, Alianza Editorial, col. Ciencias Sociales, $17^{\text {a }}$ reimp., p. 83.

${ }^{4}$ Weber, ibid., p. 92. 
Con esa base, Bobbio enfatiza el aspecto del "monopolio de la fuerza legítima" en Weber, y abunda:

Esta denominación permite comprender mejor el significado histórico de la centralización trayendo a la luz, más allá del aspecto funcional y organizativo, la evidencia más abiertamente política, que consiste en la tendencia a la superación del policentrismo del poder en favor de una concentración del mismo en una instancia parcialmente unitaria y exclusiva. La historia del nacimiento del Estado moderno es la historia de esta tensión: del sistema policéntrico y complejo de los señoríos de origen feudal se llega al Estado territorial centralizado y unitario, mediante la llamada racionalización de la gestión del poder -y por tanto, de la organización política- dictada por la evolución de las condiciones históricas materiales. [...] El Estado, en conclusión, de todo lo que se refiere a la esfera de la vida humana organizada, no directamente referida al fin espiritual. 'La distinción entre lo 'espiritual' y lo 'mundano', desde el principio introducida por los papas para fundar la supremacía de la Iglesia, desplegó su fuerza hacia el predominio y la supremacía de la política".

Los golpes de Estado producidos en el sur del continente americano, por ejemplo, en apariencia pretendían salvaguardar el orden económico. Bajo la premisa de que la función del Estado afecta, en primera instancia, al nivel económico "y más particularmente al proceso de trabajo, a la productividad del trabajo", ${ }^{6}$ resulta evidente comprender por qué el Terrorismo de Estado ha golpeado con mayor impacto a obreros argentinos y campesinos mexicanos. No obstante, existen diferencias claras, relativas a la composición de las oligarquías mexicana y argentina, para continuar con la analogía. Entre las décadas de los años sesenta y ochenta, el modelo keynesiano de un Estado poderoso implicaba trabas para las oligarquías financieras nacionales, de modo que la clase política mexicana de aquel entonces simbolizaba mayor poder, político al menos; en el caso argentino, la intención de abrir el mercado venía desde la estatización peronista de los años cincuenta.

${ }^{5}$ Bobbio, Matteucci y Pasquino, s.v . Estado Moderno, Diccionario de política, 1991, México, Siglo XXI Editores, vol. 1, pp. 564-5.

${ }^{6}$ Nicos Poulantzas, Poder político y clases sociales en el estado capitalista, 1985, México, Siglo XXI Editores, col. Sociología y política, pp. 54-5. 
La política económica emprendida por la Junta Militar argentina acabó con la industria orientada hacia el mercado interno, promulgada por el peronismo, además de que concentró la industria manufacturera en los grandes núcleos industriales, predominantemente sometidos por transnacionales, y generó mecanismos financieros para crear condiciones de acumulación (casas de bolsa, régimen de libre cambio fluctuante). Pero irónicamente, frente a esas ideas modernas del liberalismo económico, siempre detrás de todos los golpes de Estado, se hallaba la oligarquía rural, cuyos objetivos seguían representando el modelo unidimensional agroexportador, de la mano de una fuerte apertura de capitales. La poderosa oligarquía porteña complicó el fortalecimiento industrial argentino; sin duda, la era neoliberal golpeó, en efecto, antes en Argentina que en México; no obstante, la lucha de clases, la pugna por mejores condiciones económicas por parte de los estratos populares de ambas poblaciones, rebasó marcos democráticos a todas luces rígidos. Cabe aclarar que esta lucha de ninguna manera representaba un riesgo vital para la subsistencia del Estado en ambos países; sencillamente, había imposibilitado "la adecuación del Estado a los modelos de acumulación y de reconversión capitalista necesarios para mantener los niveles de reproducción y la tasa de ganancias exigidas por el bloque de poder y su dependencia imperialista"?

Del diferente éxito y del diferente grado de dominación asumidos por las fuerzas sociales, viejas y nuevas, depende la diversidad, surgida en los distintos países y en los distintos momentos históricos, en torno al modo general de organización de las relaciones sociales, como variante del mismo modelo general de Estado, detentador del monopolio de la fuerza legítima.

En su ensayo sobre las fracturas del Estado en América Latina, Sergio Zermeño expone los componentes (económico y socio histórico) del tejido social en el subcontinente. Atribuye los siguientes elementos: industrialización basada en la sustitución de importaciones, durante la década de los años cuarenta y cincuenta; "una cultura democrático burgue-

${ }^{7}$ Eduardo Luis Duhalde, El estado terrorista argentino, Quince años después, una mirada crítica, 1999, Buenos Aires, Editorial Universitaria de Buenos Aires, p. 214. 
sa y un tipo de Estado supeditados a la lógica del capital y arrastrado por una clase burguesa hegemónica". ${ }^{8}$ En efecto, durante la década de los años cincuenta, sobre todo en México, Argentina y Brasil, el modelo económico aplicado generó una sociedad consumista y una clase obrera con capacidades de negociación, por lo que es factible deducir que, si no hay avance económico en la sociedad, no hay viabilidad económica capitalista, pero sí oligárquica. No obstante, el capitalismo tardío latinoamericano debió valerse del Estado como equilibrio entre los sectores primarios exportadores y el desarrollo industrial. En el caso argentino, la debilidad de la burguesía propició con mayor prontitud la necesidad de recurrir a la inversión extranjera, de la que la oligarquía iba a aprovechar las condiciones para fugar capital. En el caso mexicano, el Estado fungió como un ente omnipotente, refiere Zermeño, con lo que se rompió la relación natural entre las fuerzas económicas del capitalismo y la organización sociopolítica. ${ }^{9}$

En México, como en otros países de América Latina, ante el raquitismo de la burguesía, el Estado se destinó a sí mismo la función de regulador de los intereses sociales y promotor del desarrollo económico [...] En realidad su labor estuvo destinada a promover los intereses de una clase, aquella que integraban los industriales y comerciantes, los banqueros y financieros, los capitalistas, ya fueran nacionales o extranjeros. Para ello se valió de las clases obrera y campesina. ${ }^{10}$

\section{Sobre Estado militar}

Resulta ineludible hacer mención de ciertos elementos relativos a la militarización del subcontintente. Eduardo Luis Duhalde, jurista argentino especializado en derechos humanos, se refiere a Tomás Vasconi para presentar una definición de Estado militar, entendido éste "como

${ }^{8}$ Sergio Zermeño, Estado y política en América Latina, 1988, México, Siglo XXI Editores, col. Sociología y Política, p. 61.

${ }^{9}$ Ibid. p. 61.

${ }^{10}$ Arturo Anguiano, Cien años de lucha de clases en México, 1876-1976, 1985, México, Ediciones Quinto Sol, Tomo 2, p. 108. 
el aparato represivo fundamental del Estado burgués que suprime, subordina y asume las funciones del resto de los elementos del Estado democrático (poderes de la federación, garantías individuales). En el caso latinoamericano, las oligarquías financieras y otros sectores conservadores en el poder, harán uso de la dictadura para asegurar su hegemonía". ${ }^{11}$ Las características del Estado militar, según plantea Duhalde, son:

1. Militarización del aparato estatal.

2. Militarización y subordinación de la sociedad civil.

3. Ausencia de límites jurídicos al ejercicio del poder.

4. Otorgamiento de atribuciones discrecionales a órganos administrativos.

5. Alto contenido represivo.

6. Sustentación en el capitalismo como base social exclusiva.

7. Concepción tecnocrática al servicio de proyectos acordes con los intereses del sector hegemónico.

8. Expresa alineación al bloque capitalista. ${ }^{12}$

La gran apología del Estado militar es la invocación de la guerra, la guerra contra la subversión. En efecto, ante la sordera del Estado democrático para atender sus derechos y demandas, una vez agotadas las instancias legales y resquebrajada incluso la apariencia de la legalidad constitucional, los brotes insurreccionales -por más desorganizados que estén los movimientos guerrilleros- se producen al "haberse agotado las posibilidades de la lucha cívica". ${ }^{13}$ Así, el Estado militar logra establecer una ideología jurídica basada en la guerra contra el enemigo desestabilizador; entonces, por encima de la ley, está la supervivencia del Estado.

\section{Sobre régimen político}

Bobbio define al régimen político como el conjunto de las instituciones que regulan la lucha por el poder y de los valores que animan la vida de

${ }^{11}$ Tomás Vasconi, Gran capital y militarización en América Latina, 1978, México, Era, p. 53; v. también Duhalde, op. cit., p. 213.

${ }^{12}$ Duhalde, op. cit. pp. 134, 215.

${ }^{13}$ Ernesto Guevara, Escritos y Discursos, 1977, La Habana, Editorial de Ciencias Sociales, Tomo 1, p. 34. 
tales instituciones. Las instituciones constituyen la estructura organizativa del poder político, que selecciona a la clase dirigente y asigna a los diversos individuos comprometidos en la lucha política su papel. ${ }^{14}$

Sobre la estructura organizativa del poder político, Weber explica que la empresa de dominación requiere una administración con dos características fundamentales: "la orientación de la actividad humana hacia la obediencia a aquellos señores que se pretenden portadores del poder legítimo", y "el poder de disposición, gracias a dicha obediencia, sobre aquellos bienes necesarios para emplear el poder físico: equipo de personal administrativo y medios materiales de administración". ${ }^{15}$

Al respecto, Arnaldo Córdova ofrece un panorama no muy alentador acerca del objeto del régimen político en el México posrevolucionario:

Las repercusiones de la concentración del poder mediante un partido hegemónico como el PNR derivaron en un gobierno paternalista y autoritario que se fue institucionalizando a través de los años; en él se ha dotado al Ejecutivo de poderes extraordinarios permanentes que prevén un dominio absoluto sobre las relaciones de propiedad. Del autoritarismo derivado del carisma del caudillo revolucionario, se pasó con el tiempo al autoritarismo del cargo institucional de la presidencia de la república. ${ }^{16}$

Para efectos de represión y Terrorismo de Estado, no existe diferencia alguna en el cambio de poder del caudillo revolucionario al gobernante civil. Lo anterior se comprende a partir de otra premisa definida por Bobbio:

El nexo entre la estructura del régimen y valores, se entiende, sin embargo, en el sentido de que la elección de un régimen implica de por sí límites a la libertad de acción del gobierno y es, en consecuencia, la elección de una política fundamental, cuyas expresiones históricas pueden ser (y de hecho lo son) sensiblemente contrastantes entre sí, si bien orientadas por los mismos principios generales. ${ }^{17}$

${ }^{14}$ Bobbio et al., s. v. Régimen político, op. cit., p. 1409.

${ }^{15}$ Weber, op. cit., pp.87-8.

${ }^{16}$ Arnaldo Córdova, La formación del poder político en México, 1990, México, Ediciones Era, col. Problemas de México, p. 34.

${ }^{17}$ Bobbio, op. cit., p. 1410. 


\section{Sobre gobierno}

Según Bobbio, el gobierno es "el conjunto de las personas que ejercen el poder político, o sea que determinan la orientación política de una cierta sociedad [...] el poder del gobierno, estando ordinariamente institucionalizado, sobre todo en la sociedad moderna, está asociado normalmente con la noción de estado". ${ }^{18}$

El gobierno constituye un aspecto del Estado. No sólo simboliza un conjunto de personas que detentan el poder de gobierno, sino el conjunto de los órganos a los que institucionalmente les está confiado el ejercicio del poder. Son las instituciones estatales las que llevan a cabo la organización política de la sociedad y que, en su conjunto, constituyen lo que ordinario se define como régimen político; son quienes tienen la tarea de manifestar la orientación política del Estado.

Para precisar el análisis en cuestión, Eduardo Jaramillo Navarrete apunta que "los gobiernos mexicanos [...] empeñaron su discurso y su acción en el encubrimiento de la naturaleza capitalista del Estado mexicano mostrando a su gobierno como 'árbitro regulador de la vida social'. Cárdenas decía: "sólo el Estado tiene un interés general y, por eso, sólo él tiene una visión de conjunto". ${ }^{19}$

Debido a la naturaleza capitalista del Estado mexicano, al corporativizar a las fuerzas sociales de entonces, el ejercicio político de Cárdenas no se correspondía sino con la lógica de acumulación de capital, acendrada en el modelo de desarrollo del Estado capitalista tardío del país. Para eso, se requerían regímenes políticos profundamente autoritarios. El aparente cambio de rumbo en los destinos de México, con la elección de Ávila Camacho y la de Alemán Valdés, representaba, en el fondo, la continuación de la naturaleza del Estado mexicano. El otro elemento sustancial en la identificación del Estado capitalista tardío es su carácter de subordinación respecto del Estado capitalista desarrollado. La hegemonía que éste ha de imponer sobre el Estado tardío latinoamericano repercutirá

${ }^{18}$ Op. cit., p. 710.

${ }^{19}$ Eduardo Jaramillo Navarrete, Estado, régimen político y acumulación de capital en México, 1920-1940, 1992, México, UNAM, Tesis de licenciatura, Ciencias Políticas y Administración Pública, Facultad de Ciencias Políticas, p. 12. 
en el Terrorismo de Estado por medio de regímenes políticos cuyo interés primordial se centra en la acumulación y concentración de capital, por encima de cualquier posible relación con las fuerzas sociales.

No obstante, Bobbio aclara que la supremacía del gobierno está garantizada por la tendencia a monopolizar el uso de la fuerza:

Un gobierno será fuerte si se funda en el consenso, mientras que ningún gobierno podrá subsistir a la larga si está constreñido a imponerse siempre por la fuerza. Aunque el liberalismo, la democracia y el socialismo hayan contribuido a ampliar la base social del poder y, en consecuencia, hayan dado inicio a un proceso de humanización de la vida política, el ejército, la policía, las cárceles, etc. constituyen aún el fundamento último sobre el que descansa el poder de gobierno. ${ }^{20}$

En efecto, dada la incapacidad del Estado capitalista tardío latinoamericano de satisfacer las exigencias económicas, sociales, culturales y políticas de la sociedad civil, que entran en conflicto de intereses entre los diversos estratos, la fuerza militar -mediante la dictadura de la Junta Militar o del poder militarizado- se revela como el único instrumento de salvación, el cual, además, habrá de suprimir cualquier viso de garantía constitucional. Sergio Zermeño afirma que "una sociedad fuerte limita la capacidad dirigente, primigenia, hegemónica del Estado". ${ }^{21}$

En el caso argentino, la enorme contradicción que se presenta por parte del régimen político emanado de la dictadura militar, radica en el intento de pretender eliminar, con justificaciones ideológicas, la fuerza de trabajo que echa a andar el motor del propio Estado, y volver a un Estado semifeudal donde las fuerzas productivas tienen mayor influencia en las relaciones agrarias. Al amparo de la oligarquía terrateniente y estanciera, aparecerá la figura financiera especulativa que provoca, por su misma naturaleza, el hundimiento del anacrónico y contradictorio proyecto militar. Perón comprendió que el Estado debía intervenir en el ámbito económico a partir de la nacionalización de empresas dentro del proceso de concentración de capital, pero sus enemigos no.

${ }^{20}$ Bobbio, op. cit., p. 711.

${ }^{21}$ Zermeño, op. cit., p. 69. 
Como efecto de la lucha de clases, la ruptura latinoamericana en su forma de gobierno democrático se encontró durante los años sesenta en una encrucijada difícil de resolver. Al respecto, Ernesto Guevara -conocido y caracterizado por una extrema concepción política-, explicaba las razones del endurecimiento del Estado:

La democracia representativa es muy útil y es algo que en determinados momentos los pueblos necesitan, para tener un control continuo de su política. Ahora, cuando la democracia representativa es la aristocracia, cuando se basa en toda una serie de privilegios, y cuando está encaminada directamente a suprimir las formas de expresión del pueblo, a través, por ejemplo, de no dejar votar al analfabeto en países que tienen el 65 por ciento de analfabetos, de no dejar votar al que no tiene un caudal suficiente -como sucede en algunos países-, sencillamente violar las urnas -como sucede en otros-, entonces la democracia representativa se convierte en una farsa. En un momento dado, la farsa es tan grande que la sociedad reacciona: en ese momento la democracia representativa suele abandonar su careta y entonces se convierte en otra cosa, lo que los norteamericanos llaman "gobierno fuerte". 22

Finalmente, habría que citar a Rousseau acerca de la forma de gobierno que México ha vivido desde la posrevolución, en cuanto a que, con la democracia directa, el pueblo "piensa que es libre y se engaña, lo es solamente durante la elección de los miembros del parlamento: tan pronto como éstos son elegidos, vuelve a ser esclavo, o es nada. El uso que hace de su libertad en los cortos momentos que la disfruta es tal, que bien merece perderla". ${ }^{23}$ El drama para el caso mexicano es todavía mayor, puesto que ni siquiera se respeta la libertad en el ejercicio del voto.

\section{Sobre poder}

Esbozado de manera muy general como la capacidad o posibilidad de obrar, de producir efectos, apunta Bobbio que en sentido social - esto

${ }^{22}$ Guevara, op.cit., p. 102.

${ }^{23}$ Juan Jacobo Rousseau, El contrato social o principios de derecho político, 1987, México, Porrúa, 8 ed., p. 51. 
es, en relación con la vida del hombre en sociedad- "el poder se precisa y se convierte de capacidad genérica de obrar, en capacidad del hombre para determinar la conducta del hombre: el poder del hombre sobre el hombre. El hombre no es sólo el sujeto, sino también el objeto del poder social". ${ }^{24}$

Pero en tanto fenómeno social, Bobbio nos aclara que es necesario contextualizar el poder, esto es, entenderlo dentro de un marco de referencia: "Para Weber, las relaciones de mandato y obediencia más o menos continuas en el tiempo, que se hallan típicamente en la relación política, tienden a basarse no solamente en fundamentos materiales o en la pura costumbre de obedecer que tienen los sometidos, sino también y principalmente en un específico fundamento de legitimidad. De este poder legítimo, [...] Weber individualizó tres tipos "puros": el poder legal, el poder tradicional y el poder carismático". ${ }^{25}$ En el apartado de legitimidad, recurriremos a los conceptos de carisma, tradición y legalidad expresados por Weber en su obra El político y el científico.

Si se toma en cuenta que, como refiere Poulantzas, el Estado posee la función particular de construir el factor de cohesión de los niveles de una formación social -esto es, un elemento organizativo y de cohesión-, es posible deducir que la acción paradójica de contravenir el orden legal está claramente maquinada, en tanto que el poder no está situado en los niveles de las estructuras, sino en su propio ejercicio por parte de una clase determinada. De ahí la necesidad, por parte de ésta, de crear un aparato legal.

Vale apuntar finalmente, una cita de Cornelius Castoriadis al respecto: "el poder no reposa esencialmente en la coerción-evidentemente siempre hay en mayor o en menor medida coerción, la cual, sabemos, puede alcanzar formas monstruosas-, sino sobre la interiorización, por los individuos socialmente fabricados, de las significaciones instituidas por la sociedad considerada". ${ }^{26}$ Tampoco hay que perder de vista que el poder no doblega, sino neutraliza la voluntad de sobre quien se ejerce, al menos en su expresión saludable.

${ }^{24}$ Bobbio, op. cit., p. 1217.

${ }^{25}$ Bobbio, ibid., p. 1224.

${ }^{26}$ Apud Duhalde, op. cit., p. 45. 


\section{Sobre legalidad}

La legalidad debiera ser un atributo y un requisito del poder, de modo que un poder es legal -o actúa legalmente o tiene el carácter de legalidad-, cuando se ejerce en el ámbito o de acuerdo con leyes establecidas o de algún modo aceptadas. Para diferenciar entre legalidad y legitimidad, se puede emplear la legalidad a propósito del ejercicio del poder y la legitimidad a propósito de la titularidad: un poder legítimo es un poder cuyo título está fundado jurídicamente; un poder legal es el que se ejerce de acuerdo con las leyes. ${ }^{27}$ Los militares argentinos expidieron más de mil leyes y decretos que, en su mayoría, contravenían la Constitución de la República Argentina antes del golpe militar. Lo contrario de un poder legítimo es un poder arbitrario; lo contrario de un poder legal es un poder de hecho.

En este sentido, el principio de legalidad es aquel con el cual todos los órganos del Estado, es decir, todos los órganos que ejercen un poder público, actúan dentro del ámbito de las leyes, salvo en casos excepcionales. El principio de legalidad tolera el ejercicio direccional del poder, pero excluye el ejercicio arbitrario.

Weber diferencia el poder regido por las leyes del poder personal: "mientras en el caso del poder tradicional se obedece a la persona del señor y en el caso del poder carismático se obedece a la persona del jefe, en el caso del poder legal el ciudadano obedece al 'ordenamiento impersonal estatuido legalmente y a los individuos puestos al frente del mismo en virtud de la legalidad formal de las prescripciones y en el ámbito de las mismas'."28

\section{Sobre legitimidad}

Definida como el atributo del Estado, que consiste en la existencia de una parte relevante de la población de un grado de consenso tal que

${ }^{27}$ Bobbio, op. cit., p. 890 .

${ }^{28}$ Bobbio, ibid., p. 891. Cfr. también Economia e Societá, 1961, Milan, p. 210. 
asegure la obediencia sin que sea necesario (salvo en casos marginales) recurrir a la fuerza, Weber distingue tres tipos de justificaciones internas o fundamentos de la legitimidad:

En primer lugar, la legitimidad del eterno ayer, de la costumbre consagrada por su inmemorial validez y por la consuetudinaria orientación de los hombres. Es la legitimidad "tradicional" [...] En segundo término, la autoridad de la gracia (carisma) personal y extraordinaria, la entrega puramente personal y la confianza [...] Es esta autoridad "carismática" la que detentaron los profetas o, en el terreno político, los jefes guerreros elegidos, los gobernantes plebiscitarios, los grandes demagogos o los jefes de los partidos políticos. Tenemos, por último, una legitimidad basada en la "legalidad", en la creencia en la validez de preceptos legales y en la "competencia" objetiva fundada sobre normas racionalmente creadas, es decir, en la orientación hacia la obediencia a las obligaciones legalmente establecidas". ${ }^{29}$

Así, el poder (como si se tratara de un ente) trata de ganarse el consenso para que se le reconozca como legítimo, transformando la obediencia en adhesión. La legitimidad es, pues, una necesidad del Estado. Referido a las formas de gobierno democráticas y autocráticas que se valen del Terrorismo de Estado, "como el poder determina siempre, por lo menos en parte, el contenido del consenso, que puede ser, por consiguiente, más o menos forzado, no parece lícito darle el atributo de legítimo tanto a un Estado democrático como a un Estado tiránico por el solo hecho de que en ambos se manifiesta la aceptación del sistema". ${ }^{30}$

\section{Sobre Estado de excepción}

Se comprende que el Estado moderno ejerce el uso legítimo de la fuerza y el poder, a los que debe limitar. Como parte de sus propios mecanismos de control, el Estado moderno prevé medidas de excepción del poder

${ }^{29}$ Weber, op. cit., p. 85.

${ }^{30}$ Bobbio, op. cit., p. 896. 
legítimo. La Constitución Política de los Estados Unidos Mexicanos señala, en sus artículos 29 y 136, que:

En los casos de invasión, perturbación grave de la paz pública o de cualquier otro que ponga a la sociedad en grave peligro o conflicto, solamente el Presidente de los Estados Unidos Mexicanos de acuerdo con los Titulares de las Secretarías de Estado y la Procuraduría General de la República $[\ldots]$ podrá suspender en todo el país o en lugar determinado las garantías que fuesen obstáculo para hacer frente, rápida y fácilmente a la situación.

El artículo 136 se refiere a la vigencia y aplicación de la Constitución, la cual "no perderá su fuerza y vigor aún cuando por alguna rebelión se interrumpa su observancia". ${ }^{31}$ En el caso de la Constitución de la República Argentina, en su artículo 23 establece que: "En caso de conmoción interior o de ataque exterior que ponga en peligro el ejercicio de esta Constitución y de las autoridades creadas por ella, se declarará en estado de sitio la provincia o territorio donde exista la perturbación del orden, quedando suspendidas allí las garantías constitucionales". ${ }^{32}$

Apunta Fernando Rojas acerca del estado de excepción: "Un subaparato asume generalmente una abierta posición de mando sobre los restantes, los opaca y los relega a una vida vegetativa de simples transmisores o ejecutores de órdenes superiores. Son los síntomas del llamado Estado o régimen de excepción". ${ }^{33}$ Entre sus características primordiales, resalta una estructura orgánica jerárquica y centralizada, toma de decisiones en apariencia sin juicio valorativo e intenciones vitalicias sobre el ejercicio del poder. Pero el Terrorismo de Estado no es privativo de los Estados de excepción.

Como efecto de los golpes de Estado sufridos en 1930, 1943, 1955, 1962 y 1966, en el caso argentino dichas medidas excepcionales fueron

${ }^{31}$ Constitución Política de los Estados Unidos Mexicanos, 2009, México, Oxford University Press, p. 287.

${ }^{32}$ Constitución Política de la Nación Argentina, http://www.bibliojuridica.org/libros $/ 5 / 2144 / 46$.pdf

${ }^{33}$ Fernando Rojas, Estado y Politica en América Latina, 1988, México, Siglo XXI Editores,

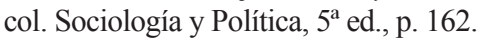


rebasadas por regímenes de facto, cuyos gobiernos militares asumieron de manera momentánea el poder y poco tiempo después llamaron al restablecimiento del Estado democrático por medio del sufragio. Si bien se trata igualmente de un Estado de excepción, el caso del golpe de Estado de 1976 es radicalmente distinto.

\section{Sobre violencia institucional}

Vale cuestionar si existen niveles de legitimación no sólo por parte del Estado, sino de la sociedad misma, de la violencia institucional, para definir hasta dónde llega la justificación del uso de la violencia por parte de la sociedad, por lo cual el Estado la ejerce sin la preocupación de responder por los efectos que dicho uso puedan implicar en la misma sociedad. El grado de profundidad con el que la sociedad es capaz de apoyar el uso de la violencia institucional es proporcional a la culpa que el Terrorismo de Estado le achaca a ésta, para minarla y responsabilizarla como cómplice. La definición que ofrece Duhalde se refiere a la violencia institucional como "una forma de relación social impuesta, por medio de la fuerza física y/o la coerción psicológica, consistente en la realización del poder acumulado a través de la vulneración del otro (individual o colectivo) con el fin de suprimir, modificar o sustituir las relaciones político-sociales preexistentes". ${ }^{34}$ En el caso mexicano, valdría concebir alguna hipótesis respecto al uso de la violencia institucional del Estado actual, valiéndose del narcotráfico como instrumento para ejercicio del poder, lo que resultaría en otro interesante motivo de estudio. Habría que analizar a profundidad si en este ejercicio se alcanzaran niveles de Terrorismo de Estado.

\section{Sobre golpe de Estado}

El Estado prevé su propia conservación a partir del uso de sus aparatos de coerción. La tarea es asignada a las fuerzas armadas y a la policía.

${ }^{34}$ Duhalde, op. cit., p. 25. 
No obstante, en la preservación de los intereses de clase, es factible que los aparatos represivos lleguen a atentar contra el régimen político y la forma de gobierno para bien de la propia naturaleza del Estado.

La diferencia entre el golpe de Estado y la revuelta militar radica en el apoyo mayoritario no sólo de las fuerzas armadas, sino de los influyentes actores políticos internos y externos; no es suficiente la mera infiltración de un grupo no militar que logre llegar a influir a un pequeño grupo de oficiales. Bobbio refiere que:

En la gran mayoría de los casos, el golpe de Estado en nuestros días implica la incautación, por parte de un grupo de militares o de las fuerzas armadas en su conjunto, de los órganos y las atribuciones del poder político, mediante una acción sorpresiva con cierto margen de seguridad y que, normalmente, reduzca la violencia inherente al acto con el mínimo empleo posible de la violencia física. ${ }^{35}$

Hoy no existe golpe de Estado sin la participación activa de, por lo menos, un grupo militar o la neutralidad-complicidad de todas las fuerzas armadas, con la participación encubierta del capital financiero.

Aunque es motivo de otro estudio, cabría preguntarse por qué Argentina, en el período 1976-83, fue tipificada como una dictadura militar, en cuanto su carácter ilegítimo -la conquista del poder por medio de un golpe de Estado, la supresión de las garantías políticas y civiles-, si entendemos la dictadura a partir de sus características romanas, según Bobbio, a saber: a) estado de necesidad con respecto a la legitimación; b) carácter excepcional de los poderes que consiste sobre todo en la suspensión de las garantías constitucionales ordinarias; c) unidad de mando (el dictador siempre es una persona cuyo poder sustituye a cualquier forma de poder colegiado); y, d) temporalidad del cargo. De esta manera, la dictadura es una magistratura monocrática, con poderes extraordinarios, pero legítimos (esto es, constitucionales). ${ }^{36}$ Argentina podría ser tipificada más en el rango de una tiranía, en tanto que "es monocrática (en su caso y recurriendo a Bobbio igualmente, es comisaria, no autocrática) tiene poderes extraordinarios, pero no es legítima y tampoco necesariamen-

${ }^{35}$ Bobbio, op. cit., p. 725.

${ }^{36}$ Ibid., p. 183. 
te temporal". ${ }^{37}$ La Junta Militar no sólo suspendió, sino que cambió la constitución de la República Argentina. En alusión a Rousseau, ellos -los militares- hicieron hablar hasta a las leyes. En su doble discurso característico, la Junta Militar se declaraba como un gobierno provisional, pero su intención era la perpetuación en el poder.

\section{Terrorismo de Estado}

Las dos grandes líneas conceptuales sobre las que se define el Terrorismo de Estado derrotan hacia caminos paralelos: finalidades políticas y aplicación contra la sociedad civil. Su piedra nodal se centra en la sistematización de las prácticas de eliminación y aniquilamiento, por parte del Estado -su régimen político o su forma de gobierno-, de dicha sociedad.

El punto de partida que deriva en el Terrorismo de Estado es la represión. Al respecto, William Schulz explica tres niveles estructurales en el ejercicio de la represión por parte del Estado, todos efecto de la naturaleza misma del Estado, y sistemáticos, pero sus alcances globales no competen sólo al ámbito estatal, sino a la concepción de acumulación de capital. ${ }^{38}$ El primero, según Schulz, se deriva de las relaciones sociales y, fundamentalmente económicas, y es global: la muerte por desnutrición de miles de niños, el analfabetismo, la violencia contra la mujer, la discriminación racial.

El segundo nivel se refiere al cumplimiento, por medio de la violencia, de las funciones públicas del Estado, dentro de marcos legales nacionales e internacionales. Y el tercero - motivo del presente estudio- es la violencia que comete el Estado atentando incluso contra las normas del derecho nacional e internacional.

El Terrorismo de Estado es, por sí mismo, un exceso. El ingrediente que determina la sutil diferencia entre represión o violencia institucional y Terrorismo de Estado - en ambos casos sistemáticos y con fines de

${ }^{37}$ Bobbio, ibid., p. 183.

${ }^{38}$ William Schulz, Terrorismo de Estado, el papel internacional de Estados Unidos, 1990, Navarra, Ediciones Txalaparta, p. 33. 
eliminación-, puede centrarse en la consideración de los métodos de desaparición de la sociedad, tipificados como no convencionales y, por supuesto, fuera de toda legalidad.

Se pueden destacar ciertas características esenciales relativas al Terrorismo de Estado aplicado como metodología en la década de los años setenta del siglo pasado: política genocida bajo el objetivo de aniquilamiento de personas; principio de autoridad basado en el terror; no responsabilidad de la autoridad en la aplicación del Terrorismo de Estado; pacto de honor entre las fuerzas participantes; desinformación mediática sobre los acontecimientos de muertes y desapariciones.

La primera gran contradicción del Terrorismo de Estado se traduce en su propia normatividad; en efecto: dada la obligación de defender cierto orden social que se contraviene cada vez más con las pugnas de los diversos estratos, aquél tuvo que desdoblar una doble cara o un doble plano de la normatividad: la parte pública, sujeta al imperio de la ley, y la clandestina, que irá adquiriendo carácter estructural en las metodologías y las funciones que deberá desarrollar para el control del poder. El papel del aparato militar se hace entonces imprescindible, ya que algunos sectores de la sociedad civil-las clases oligárquicas beneficiadas con esta política- pueden llegar a pasar por alto solamente ciertos 26 niveles de represión.

La razón de dicho desdoblamiento se finca en la mayor perversión por parte del Terrorismo de Estado: el ocultamiento del accionar, ya no ilegítimo, sino ilegal, y aún más lejos: la propia negación de las actividades. Aducir a un enfrentamiento ético en su propio quehacer sería tema de otro trabajo; para los efectos de la presente reflexión baste mencionar que funciona de dicha manera, en la penumbra, escondiendo evidencias, desinformando al ciudadano, restando certezas para lograr un mayor control a partir de las inseguridades de la sociedad; pero a la inversa, el desciframiento del Estado, por parte del individuo, se convierte en cosa menos que imposible. Es el principio del miedo a partir de la práctica arbitraria del Estado como forma de ser, cuyo desenlace es la posibilidad para cualquiera de convertirse en víctima potencial.

Los efectos intimidatorios sobre la sociedad devienen en la desaparición de los secuestrados sin dejar rastros; no obstante, la perversión 
radica justamente en la ambivalencia del acto: si bien el $62 \%$ de los secuestros en Argentina durante el período de 1976-1983 se realizó en la noche, ${ }^{39}$ los ejecutores se aseguraban de generar el suficiente ruido -altavoces, apagones, helicópteros, destacamentos numerosos- para inculcar el miedo en las zonas circunvecinas; y estaba prohibido dar información, de cualquier naturaleza, sobre el paradero de los secuestrados. Así, se siembra un eficaz terror en la población.

En la parte clandestina será en la que el Estado terrorista ha de basarse para establecer un ambiente de pánico, coerción y violencia. Su justificación radica en aparecer en tiempos de crisis profundas, en las que el aparato productivo se ha transformado, provocando desocupación, baja en los salarios y cada vez menor actividad económica por parte de la pequeña y mediana industrias nacionales. Con tales factores presentes, no es suficiente la supresión de los mecanismos de representación ni la negación de las libertades. En el caso mexicano, es interesante identificar cómo el propio sistema político, desde su origen y afincamiento, fue orillando a los movimientos y las causas que quedaban fuera de su ámbito de control mediante el uso de la violencia. De esta manera, se fue eliminando a la oposición, cada vez de forma más planificada.

El Estado terrorista aplica la doble normatividad referida para deslindarse legalmente de cualquier indicio que lo pueda relacionar directamente con la acción terrorista. Así, el gobierno mexicano brinda un apoyo solidario a los extranjeros que huyen de la muerte a manos de las dictaduras militares del cono sur, mientras aplica el mismo esquema para abatir a su disidencia. Los militares argentinos, a su vez, hablan en público: "hay que ganar la paz, pero no a costa de un baño de sangre [...] hay que lograr la convivencia ideológica, rechazando de plano la posibilidad del fascismo o de cualquier otro extremismo". ${ }^{40}$ Entretanto, los procedimientos son velados, las autoridades niegan su participación en secuestro alguno, además de negar información relacionada con los prisioneros, les vendan los ojos, usan centros de detención ocultos; los grupos operativos no se identifican, no sabe a qué jurisdicción pertenecen los destaca-

${ }^{39}$ CONADEP, Informe de la Comisión Nacional sobre la desaparición de personas, "Nunca más”, 2005, Buenos Aires, Eudeba, 6 a ed., 5 a reimpresión, p. 17.

${ }^{40}$ Duhalde, op. cit., p. 254. 
mentos militares. En esta forma se oculta el accionar del Terrorismo de Estado.

Los canales mediante los cuales las estructuras, militar (en el caso argentino) y militarizada (en cuanto al mexicano), se sustentaron para contrarrestar la influencia ideológica del enemigo, por mantenerse en el dominio de lo privado, fueron aquellos que lograron plegarse sin mayores consecuencias al control hegemónico: la Iglesia, los medios de comunicación, las estructuras políticas y empresariales, entre otros sectores, ayudaron a justificar el contexto violento del Terrorismo de Estado.

Resulta ineludible hacer mención de la relación entre el victimario y la víctima en el Terrorismo de Estado. Un precepto claro se despliega en torno a cómo un ser humano sin grandes psicopatías es capaz de torturar y asesinar de manera sistemática. ¿Cómo puede entenderse que un soldado nacido en la zona de maniobra puede ser capaz de abstraerse de su propio entorno y eliminar a quienes pueden ser su propia familia? El fondo es la cosificación de la víctima, es decir, la negación de la condición humana de los otros, lo que permite mecanizar la metodología del Terrorismo de Estado como si se tratara de producción en serie (eliminación en serie). Resulta interesante reflexionar sobre la analogía que, sobre cosificación, puede significar aquello que nos explica Rojas acerca del valor monetario: "Para la burguesía, la moneda, la mercancía, los precios, el Estado, el derecho, las ideas, son conceptos cosificados eternos como las esencias cuyo contenido varía según las relaciones de la época". ${ }^{41}$ Bastaría añadir a la exposición anterior la palabra persona, y apuntar que dicho ocultamiento de la violencia por parte del Estado capitalista y del Terrorismo de Estado permite a la ideología dominante no reconocerla. De ahí la serie de manifestaciones que en el pasado se entendían como cínicas y en el presente se comprenden carentes de contexto, en defensa de las juntas militares por parte de la sociedad civil; preciso: por parte de los sectores más conservadores de la sociedad civil, los cuales, una vez destapada la serie de atrocidades cometidas por el régimen que preconizaban, optaron por hacer mutis.

\footnotetext{
${ }^{41}$ Fernando Rojas, op. cit., p. 138.
} 
Resta mencionar la sistematización del Terrorismo de Estado, encarnada en aspectos como la adecuación de espacios carcelarios clandestinos, dispuestos con áreas de tortura física y psicológica, enfermerías, celdas especiales -mientras más pequeñas e incómodas, mejores efectos-, para recibir a los detenidos-desaparecidos (en México se utilizaron y se usan las bases militares y los sótanos de las oficinas de las policías estatales y federales; en Argentina la infraestructura represiva debió adecuar decenas de casas, edificios y lotes abandonados para usarlos como Centros Clandestinos de Detención); el uso del ejército para funciones políticas y policíacas; la ausencia de órdenes de aprehensión; la detención de personas y allanamientos de morada sin fundamentos legales; el robo, la violación, la crueldad, el vandalismo de los aparatos coercitivos del Estado; las justificaciones de homicidios -como "repeler la agresión" o "hechos de guerra"-; enfocar a la población como objetivo militar; toma de rehenes para operaciones de toda índole; la criminalización de las víctimas y de la sociedad; el aprovechamiento de la vulnerabilidad de la sociedad-niños, ancianos, mujeres-; las ejecuciones extrajudiciales; la tortura como forma de aniquilamiento; la desaparición de los cuerpos; el encubrimiento de los responsables intelectuales operativos de estas actividades, entre otros muchos. Un ejemplo: en el capítulo 9 de la versión preliminar del Informe Final de la Fiscalía Especial para Movimientos Sociales y Políticos del Pasado (FEMOSPP) se refiere que, en el caso mexicano, el entonces titular de la Dirección Federal de Seguridad (DFS), Fernando Gutiérrez Barrios, declaró a Rosario Ibarra de Piedra que las desapariciones políticas correspondían a una decisión de Estado y que, para investigarlas, correspondía otra decisión de Estado. ${ }^{42}$

\section{Guerra sucia}

Existen ciertas reservas analíticas en torno al uso del término Guerra sucia. Suele debatirse que es ambiguo y poco apropiado, en función de

${ }^{42}$ Informe Final de la Fiscalia Especial para Movimientos Sociales y Politicos del Pasado FEMOSPP, Versión preliminar, capítulos 1 al 12, Versión Adobe Reader 6.0 cap. 9, p. 12. 
que no ha existido en la historia de la humanidad alguna guerra que pudiera denominarse limpia; en efecto, el término como tal no aparece en el Diccionario de Política de Norberto Bobbio. ${ }^{43}$ La así llamada 'guerra sucia' engloba los mecanismos y metodologías torcidas del Terrorismo de Estado. Cabe hacer algunas consideraciones al respecto.

La regulación internacional en la materia abarca dos grandes apartados. El primero versa sobre las formas de conducir la guerra, y el otro sobre la protección a quienes se ven involucrados, partes en pugna o civiles. El así llamado Derecho de Ginebra, firmado por México en 1952 y puesto en vigor el 29 de abril de 1953, ${ }^{44}$ confiere protección a todas aquellas personas que no forman parte de la guerra, pero que, debido a cualquier circunstancia geográfica o política, se ven irremediablemente sumidas en ella. Entre tanto, la guerra subversiva o revolucionaria, como la llamaron los franceses y para la cual elaboraron una serie de análisis y estudios que fueron puestos en práctica en 1957 en Argelia, a partir de la derrota de Dien Bien Puh, en Vietnam, tenía como fundamento la comprensión de un enemigo diferente al ejército convencional de la Segunda guerra mundial, lo que significaba que la población podría formar parte de los ejércitos adversarios, en tanto se trataba de guerras de liberación del colonialismo francés.

Los nuevos métodos de guerra franceses - conocidos en general como la Escuela francesa-implicaban tácticas operativas y sistemáticas de secuestro, tortura y desaparición de los prisioneros, y pasaban por encima de cualquier reglamentación internacional. El ejército argentino fue el primero de Latinoamérica en aprender la lección francesa; desde el año 1961 y hasta fines de esa década, asesores franceses trabajaron en el Ministerio de Defensa de la nación sudamericana. Luego otorgaron su valiosa asesoría en las escuelas norteamericanas y brasileñas, y así la guerra antisubversiva permeó en todo el continente.

Apenas un año después del último golpe de Estado en Argentina, la Junta Militar comenzó a ser blanco de la crítica internacional y debieron encontrar un discurso autoexculpatorio. "Hay muchas cosas sobre la

${ }^{43}$ Por lo menos en su edición de 1991, aunque este hecho no demerite la validez de términos sólo por no aparecer en el texto indicado.

${ }^{44}$ FEMOSPP, ibid., cap. 9, p. 1. 
Argentina que se distorsionan con fines inconfesables. Debo reconocer que la lucha contra la subversión produjo una guerra sucia que hace imposible abarcar todos los controles en los esfuerzos contra la lucha subversiva". ${ }^{45}$ Jorge Rafael Videla, presidente de la Junta, usaba el término guerra sucia por primera vez de manera pública (en el marco de la entrevista con James Carter, en el Salón Oval de la Casa Blanca, el 9 de septiembre de 1977), como excusa para encubrirse de los excesos; el término se filtró y los militares argentinos poco caso hicieron a la recomendación del entonces Secretario de Estado norteamericano, Henry Kissinger, de que "si van a matar, maten, pero háganlo rápido", ${ }^{46}$ porque venía una administración deseosa de regular en materia de derechos humanos.

Algunos años más tarde, en su defensa contra los juicios a las juntas provocados por los decretos 157/83 y 158/83, Videla reclamó para el pueblo argentino y para las Fuerzas Armadas "el honor de la victoria en una guerra que, como expresara en otras oportunidades, no fue deseada ni buscada, sino ordenada por el poder político en ejercicio del legítimo derecho de defensa de la nación agredida y que fue ejecutada con un alto espíritu de sacrificio". ${ }^{47}$ Sobre este alto espíritu, se hace inevitablemente presente la imagen del capitán de fragata argentino, Alfredo Astiz, quien balaceó por la espalda a una niña sueca que creía subversiva; quien golpeó y torturó a un par de monjas francesas que profesaban el movimiento religioso del tercer mundo; y quien se rindió dócilmente sin disparar una sola bala ante los ingleses en la isla de Georgia a su defensa, durante la guerra de las Malvinas.

Otro personaje tristemente célebre, el general Ramón J. A. Camps, titular de la jefatura de policía de la provincia de Buenos Aires durante el período en cuestión, habría de considerar que "aquella fue una guerra sucia. Los que la hicieron sucia fueron los subversivos. Ellos eligieron las formas de lucha y determinaron nuestras acciones" ${ }^{98}$ (como si se

${ }^{45}$ María Seoane y Vicente Muleiro, El dictador, historia secreta y pública de Jorge Rafael Videla, 2006, Buenos Aires, Editorial Sudamericana, col. Debolsillo, p. 343.

${ }^{46}$ María Seoane, ibid., p. 308.

${ }^{47}$ Seoane, ibid., pp. 24-5.

${ }^{48}$ Duhalde, op. cit., p. 260. 
hubiese reaccionado a un estímulo condicionado, como si no se hubiese planeado sistemáticamente desde años atrás toda la metodología del Terrorismo de Estado).

En México se creó también una estrategia de contrainsurgencia. La versión preliminar del Informe Final de la FEMOSPP señala que, en un documento fechado el 2 de julio de 1974, el Ejército mexicano señalaba que "no hay que llamarse a engaño. Que si el ejército le llama a esta gente maleantes y gavilleros es tan sólo para no deteriorar la imagen de México en el extranjero ya que, de lo que se trata, es de una guerrilla", ${ }^{9}$ además de considerar el uso del personal militar, que había tomado los cursos antisubversivos en el extranjero.

Posteriormente, el mencionado informe da cuenta de algunas tácticas de contrainsurgencia, a partir de órdenes expresas de exterminar a las gavillas de maleantes, como se referían a la guerrilla a la luz de los reflectores. Cualquier homicidio podía reportarse como cometido al repeler la agresión para que se considerara un acto de heroísmo (quizá similar al ejemplo del Capitán Astiz).

Entre los años 1973 y 1978, el informe de la FEMOSPP registra que el Estado mexicano, por medio de su aparato militar, tomó como objetivo militar a la población; realizó ejecuciones sumarias; violaciones a mujeres; torturó a niños frente a sus padres; llevó a cabo secuestros; condenas en cárceles clandestinas; desfiguraciones con gasolina a personas; criminalizó a sus víctimas; bombardeó poblaciones y efectuó vuelos de la muerte para desaparecer paquetes (término usado en México y Argentina para referirse a detenidos-desaparecidos). ${ }^{50}$ Ésas y muchas otras operaciones, similares a las realizadas durante el Proceso de Reorganización Nacional en Argentina, fueron sufridas por civiles: en 1977, la guerrilla argentina ya no existía; en México, Lucio Cabañas había muerto en diciembre de 1974.

Por tanto, no es casual que el día de hoy se vivan en México niveles de violencia comparados con cualquier guerra en el Medio Oriente. Los antecedentes de estos hechos vergonzosos pueden verificarse copiosamente en la historia del México posrevolucionario.

${ }^{49}$ FEMOSPP, op. cit., cap. 9, p. 7.

${ }^{50}$ Ibid., p. 11. 